\title{
TRANSPORT AND PERFORMANCE IN DIII-D DISCHARGES WITH WEAK OR NEGATIVE CENTRAL MAGNETIC SHEAR
}

\author{
by
}

C.M. GREENFIELD, D.P. SCHISSEL, B.W. STALLARD, E.A. LAZARUS, G.A. NAVRATIL, T.A. CASPER, J.C. DeBOO, E.J. DOYLE, R.J. FONCK, C.B. FOREST, P. GOHIL, R.J. GROEBNER, M. JAKUBOWSKI, L.L. LAO, M. MURAKAMI, C.C. PETTY, C.L. RETTIG, T.L. RHODES, B.W. RICE, H.E. ST. JOHN, G.M. STAEBLER, E.J. STRAIT, T.S. TAYLOR, A.D. TURNBULL, K.L. TRITZ, R.E. WALTZ, and the DIII-D TEAM

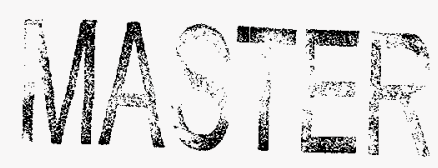


This report was prepared as an account of work sponsored by an agency of the United States Government. Neither the United States Government nor any agency thereof, nor any of their employees, makes any warranty, express or implied, or assumes any legal liability or responsibility for the accuracy, completeness, or usefulness of any information, apparatus, product, or process disclosed, or represents that its use would not infringe upon privately owned rights. Reference herein to any specific commercial product, process, or service by trade name, trademark, manuacturer, or otherwise, does not necessarily constitute or imply its endorsement, recommendation, or favoring by the United States Government or any agency thereof. The views and opinions of authors expressed herein do not necessarily state or reflect those of the United States Government or any agency thereof. 


\section{DISCLAIMER}

Portions of this document may be illegible in electronic image products. Images are produced from the best available original document. 


\title{
TRANSPORT AND PERFORMANCE IN DIII-D DISCHARGES WITH WEAK OR NEGATIVE CENTRAL MAGNETIC SHEAR
}

by

C.M. GREENFIELD, D.P. SCHISSEL, B.W. STALLARD,1 E.A. LAZARUS, 2 G.A. NAVRATIL, 3 T.A. CASPER, 1 J.C. DeBOO, E.J. DOYLE, ${ }^{4}$ R.J. FONCK, 5 C.B. FOREST, P. GOHIL, R.J. GROEBNER, M. JAKUBOWSKI, 5 L.L. LAO, M. MURAKAMI,2 C.C. PETTY, C.L. RETTIG,4 T.L. RHODES,4 B.W. RICE,1

H.E. ST. JOHN, G.M. STAEBLER, E.J. STRAIT, T.S. TAYLOR, A.D. TURNBULL, K.L. TRITZ,5 R.E. WALTZ, and the DIII-D TEAM

This is a preprint of an invited paper presented at the APS Division of Plasma Physics Meeting, November 11-15, 1996, Denver, Colorado, and to be printed in a Special Issue of Physics of Plasmas.

Work supported by U.S. Department of Energy Contracts DE-AC03-89ER51114, W-7405-ENG-48, and DE-AC05-96OR22464, and Grants DE-FG02-89ER53297, DE-FG03-86ER53266, and DE-FG02-92ER54139

\author{
${ }^{1}$ Lawrence Livermore National Laboratory \\ 2 Oak Ridge National Laboratory \\ ${ }^{3}$ Columbia University \\ 4 University of California, Los Angeles \\ 5 University of Wisconsin-Madison
}

\section{GENERAL ATOMICS PROJECT 3466 DECEMBER 1996}




\title{
Transport and performance in DIII-D discharges with weak or negative central magnetic shear
}

\author{
C.M. Greenfield, D.P. Schissel, B.W. Stallard, ${ }^{\text {a) }}$ E.A. Lazarus, ${ }^{\text {b) }}$ \\ G.A. Navratil, ${ }^{\text {c) }}$ K.H. Burrell, T.A. Casper, ${ }^{\text {a) J.C. DeBoo, E.J. Doyle, }}$, \\ R.J. Fonck, ${ }^{\text {e) }}$ C.B. Forest, P. Gohil, R.J. Groebner, M. Jakubowski,e) \\ L.L. Lao, M. Murakami, b) C.C. Petty, C.L. Rettig,d) T.L. Rhodes, d) \\ B.W. Rice, a) H.E. St. John, G.M. Staebler, E.J. Strait, T.S. Taylor, \\ A.D. Turnbull, K.L. Tritz, ${ }^{\text {e) }}$ R.E. Waltz, and the DIII-D Team
}

General Atomics, P.O. Box 85608, San Diego, California 92186-5608

Discharges exhibiting the highest plasma energy and fusion reactivity yet realized in the DIII-D tokamak [Plasma Physics and Controlled Nuclear Fusion Research, 1986 (International Atomic Energy Agency, Vienna, 1987), Vol. I, p. 159] have been produced by combining the benefits of a hollow or weakly sheared central current profile [Phys. Plasmas 3, 1983 (1996)] with a high confinement ( $\mathrm{H}$-mode) edge. In these discharges, low power neutral beam injection heats the electrons during the initial current ramp, and "freezes in" a hollow or flat central current profile. When the neutral beam power is increased, formation of a region of reduced transport and highly peaked profiles in the core often results. Shortly before these plasmas would otherwise disrupt, a transition is triggered from the low (L-mode) to high ( $\mathrm{H}$-mode) confinement regimes, thereby broadening the pressure profile and avoiding the disruption. These plasmas continue to evolve until the high performance phase is terminated nondisruptively at much higher $\beta_{\mathrm{T}}$ (ratio of plasma pressure to toroidal magnetic field pressure) than would be attainable with peaked profiles and an L-mode edge. Transport analysis indicates that in this phase, the ion diffusivity is equivalent to that predicted by Chang-Hinton neoclassical theory over the entire plasma volume. This result is consistent with suppression of turbulence by locally enhanced $\vec{E} \times \vec{B}$ flow shear, and is supported by observations of reduced fluctuations in the plasma. Calculations of performance in these discharges extrapolated to a deuterium-tritium fuel mixture indicates that such plasmas could produce a DT fusion gain $Q_{\mathrm{DT}}=0.32$.

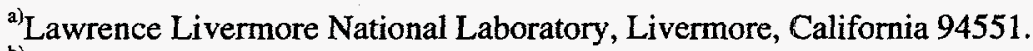

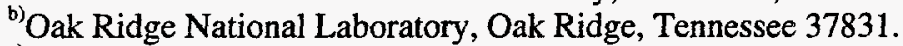

${ }^{c)}$ Columbia University, New York, New York 10027.

${ }^{d}$ University of California, Los Angeles, California 90024.

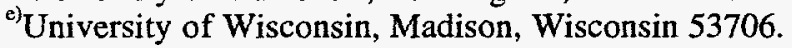




\section{CONTENTS}

Abstract $\ldots \ldots \ldots \ldots \ldots \ldots \ldots \ldots \ldots \ldots \ldots \ldots \ldots \ldots \ldots \ldots \ldots \ldots \ldots \ldots \ldots \ldots$ iii

I. Introduction $\ldots \ldots \ldots \ldots \ldots \ldots \ldots \ldots \ldots \ldots \ldots \ldots \ldots \ldots \ldots \ldots \ldots$

II. Performance Optimization $\ldots \ldots \ldots \ldots \ldots \ldots \ldots \ldots \ldots \ldots \ldots$

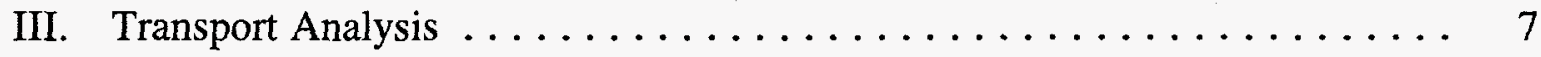

III.A. Internal Transport Barrier Formation $\ldots \ldots \ldots \ldots \ldots \ldots \ldots \cdot 7$

III.B. Extension of the Transport Barrier to the Entire Plasma . . . . . . 10

III.C. Dependence of Transport on Magnetic Shear . . . . . . . . 12

IV. Extrapolation to DT Operation $\ldots \ldots \ldots \ldots \ldots \ldots \ldots \ldots \ldots \ldots \ldots$

V. Summary and Conclusions $\ldots \ldots \ldots \ldots \ldots \ldots \ldots \ldots \ldots \ldots$

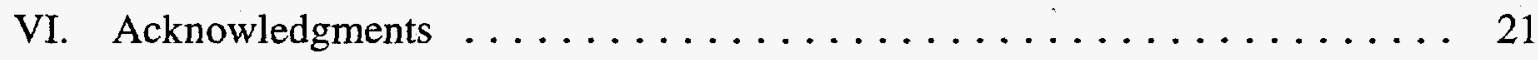

VII. References $\ldots \ldots \ldots \ldots \ldots \ldots \ldots \ldots \ldots \ldots \ldots \ldots \ldots \ldots \ldots \ldots \ldots$

Figures

1. Broader density profiles in plasmas with an $\mathrm{H}$-mode edge $\ldots \ldots \ldots \ldots \ldots$

2. Comparison of similar discharges with and without the stimulated

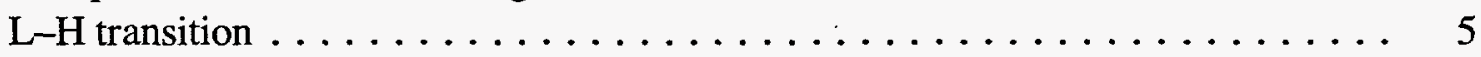

3. Time evolution of a discharge with high fusion gain $\ldots \ldots \ldots \ldots \ldots \ldots$

4. Ion temperature at several different positions in the plasma $\ldots \ldots \ldots \ldots .8$

5. Shearing rate $\omega_{E \times B}$ and maximum calculated growth rate $\ldots \ldots \ldots \ldots$.

6. Time evolution of $\mathrm{H}$-mode discharges with weak and negative central magnetic shear . . . . . . . . . . . . . . . . 11

7. Ion temperature, rotation, total, and purely conductive diffusivity profiles $\ldots \ldots 12$

8. H-mode edge discharges with negative and weakly positive magnetic shear.... . 13

9. L-mode edge discharges with strongly and weakly negative central

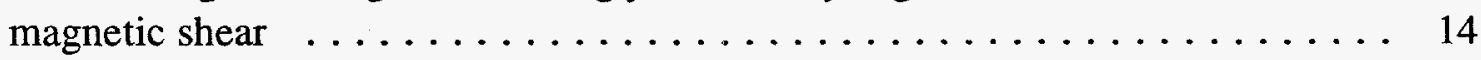

10. Central particle densities calculated in a discharge with a 50:50 DT mix $\ldots \ldots 16$

Table

I. Parameters of highest performance $\mathrm{H}$-mode discharges with weak

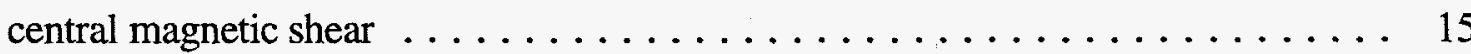




\section{INTRODUCTION}

An important challenge in magnetic fusion research is the development of an advanced configuration capable of achieving conditions of high reactivity in a compact, economical device. Recent experiments in the DIII-D tokamak, ${ }^{1}$ a modest size $(R=1.67 \mathrm{~m})$ low magnetic field $\left(B_{\mathrm{T}}=2.1 \mathrm{~T}\right)$ device, have demonstrated progress in this direction, achieving high fusion power $P_{\mathrm{DD}} \leq 28 \mathrm{~kW}$ in deuterium plasmas, which extrapolates to DT fusion power gain up to $Q_{\mathrm{DT}} \approx 0.32$.

This enhanced performance is obtained via a combination of factors. First, stability at high $\beta_{\mathrm{T}}$ is improved by combining a region with a hollow or weakly sheared current profile in the core with broad pressure profiles (stability of these discharges is discussed in detail in a companion paper by Strait $e t a l .^{2}$ ). Second, transport is reduced to neoclassical ${ }^{3}$ values throughout most of the plasma cross-section which results in high confinement, allowing the plasma to take advantage of the high beta limits with relatively low ( $\leq 20 \mathrm{MW})$ applied heating power. The results with these simple profile control tools are impressive, and give reason for optimism when more sophisticated tools become available in the future.

Enhanced performance has been previously reported in DIII-D $D^{4-6}$ in plasmas with weak or negative central magnetic shear and a low confinement ( $\mathrm{L}-$-mode) edge. In these experiments, the aforementioned region exhibiting a hollow or flat current profile was used to improve performance in the core. However, these plasmas typically have peaked profiles, and invariably disrupt at moderate $\beta_{\mathrm{N}} \leq 2\left(\beta_{\mathrm{N}}=a B_{\mathrm{T}} \beta_{\mathrm{T}} / l_{\mathrm{P}}\right)$ where $a$ is the plasma minor radius in $\mathrm{m}, B_{\mathrm{T}}$ is toroidal magnetic field in $\mathrm{T}, I_{\mathrm{P}}$ is plasma current in $\mathrm{MA}$, and $\beta_{\mathrm{N}}$ is normalized beta in $\mathrm{m}-\mathrm{T} / \mathrm{MA})$.

In recent experiments, controlled transitions from $\mathrm{L}$-mode to the high confinement ( $\mathrm{H}$-mode) regime were used to broaden the pressure profile and stabilize the magnetohydrodynamic (MHD) activity which leads to a disruption. 2,7 This allowed the plasmas to continue to evolve, reaching higher $\beta_{\mathrm{T}}$ and higher reactivity before the high performance phase terminates in a non-disruptive fashion. These plasmas, which can reach $\beta_{\mathrm{N}} \approx 4$ and $H \approx 4$ (confinement time relative to the ITER-89P8 scaling relation), tend to exhibit neoclassical ion transport over nearly their entire cross section.

In Section II of this paper, we will discuss the global results of experiments targeted at optimizing performance by combining the two effects of central magnetic shear and the $\mathrm{H}$-mode edge. In Section III, detailed transport analysis of discharges with or negative central magnetic shear will be shown, along with evidence to support the paradigm of turbulence stabilization by sheared $\vec{E} \times \vec{B}$ velocity as the primary effect responsible for the enhanced performance once the second stability regime is accessed in the core. In Section IV, we will present the results of studies of extrapolation of these discharges to DT plasmas. Finally, the work will be summarized in Section V. 


\section{PERFORMANCE OPTIMIZATION}

As has previously been reported ${ }^{4-6}$ high fusion performance plasmas with weak or negative central magnetic shear and sufficient neutral beam power have been observed to develop a region of improved stability and confinement in the core. Plasmas heated by rf are discussed in Ref. 9. Such plasmas are formed by heating the electrons with neutral beams during the initial current ramp, in order to reduce the core resistivity and "freeze in" the current profile.

In these experiments, the highest levels of fusion performance (factor of two increase from the highest performance VH-mode plasmas ${ }^{10)}$ observed in DIII-D were established in plasmas with an $\mathrm{L}$-mode edge and a region of reduced transport corresponding to the region of reversed magnetic shear in the core. However, these plasmas invariably disrupt due to the very high central pressure gradient. ${ }^{11}$ In such cases, performance is limited by MHD instabilities.

Predictions based on ideal MHD 12 anticipated that such disruptions could be avoided by broadening the pressure profiles to reduce the peak value of $p^{\prime}=\partial p / \partial \psi$, as typically occurs following transition from the low to high confinement regimes (L-H). When an $\mathrm{L}-\mathrm{H}$ transition is initiated prior to the disruption, the consequent broadening of the pressure profile leads to avoidance of the instability, and the plasma continues to evolve to further enhanced performance (Fig. 1). In such experiments in DIII-D, up to $28 \mathrm{~kW}$ of DD fusion power was produced.

In order to perform the experiment, a control algorithm was developed to effectively switch the plasma between $\mathrm{L}$ - and $\mathrm{H}$-mode. Rapid motion from a nominally double-null divertor shape biased toward the upper poloidal field null with the ion $\nabla B$ drift pointing away from the controlling $X$-point, to one with a bias toward the lower poloidal field null with the ion $\nabla B$ drift pointed towards the controlling $\mathrm{X}$-point [Fig. (2a)] results in a swift reduction in the H-mode power threshold. ${ }^{13}$ Such motion is often followed immediately by an L-H transition ${ }^{7}$ which broadens the pressure profile and allows the discharge to continue to evolve (Fig. 2). One interesting feature of these transitions is that in the presence of a pre-existing internal transport barrier in the L-mode phase, the threshold power becomes elevated. This appears to be a consequence of the fact that a large portion of the applied power is contained in the core, reducing the power flow across the boundary which is needed to obtain the transition. ${ }^{13}$ In order to successfully utilize the $\mathrm{L}-\mathrm{H}$ transition as a profile control tool, the neutral beam power in the highest performance discharges was raised in two steps (Fig. 3), with the $\mathrm{L}-\mathrm{H}$ transition triggered at the intermediate power level. 


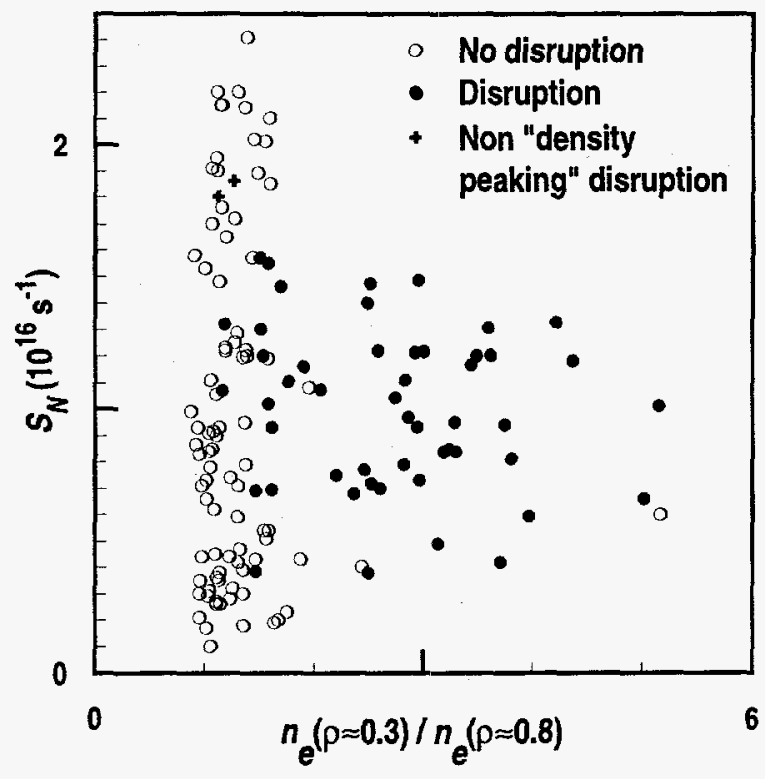

Fig. 1. The broader density (and therefore pressure) profiles in plasmas with an H-mode edge result in higher reactivity and fewer disruptions. The highest neutron rates in DIII-D have been produced in discharges with broad density profiles, indicated here by a low ratio of the densities measured at two locations by Thomson scattering. Note that the character of many of the disruptions with broad density profiles, including the two highest reactivity disruptive discharges shown, is different from those with more highly peaked density profiles. 
(a)

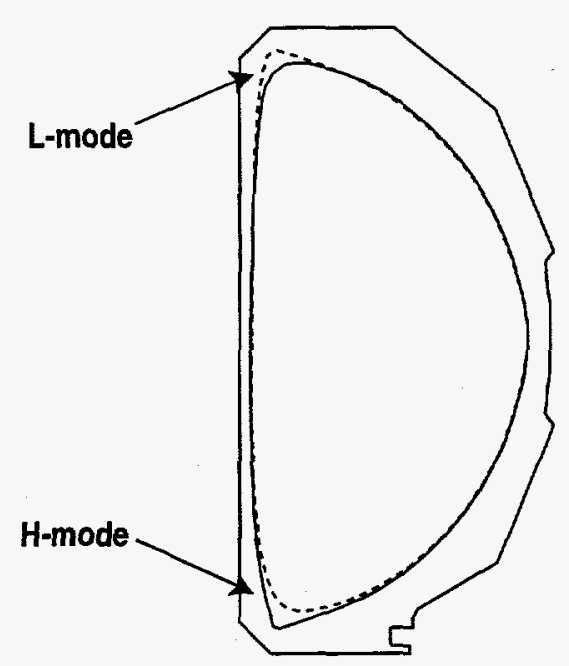

(b)

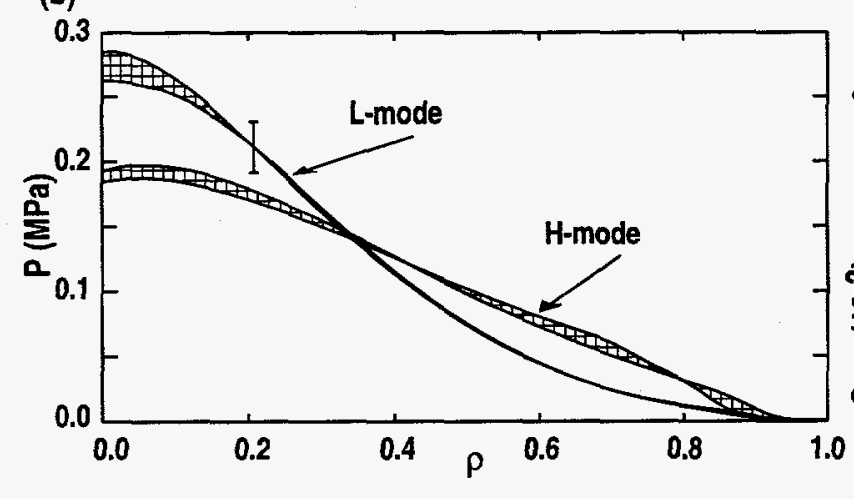

(c)
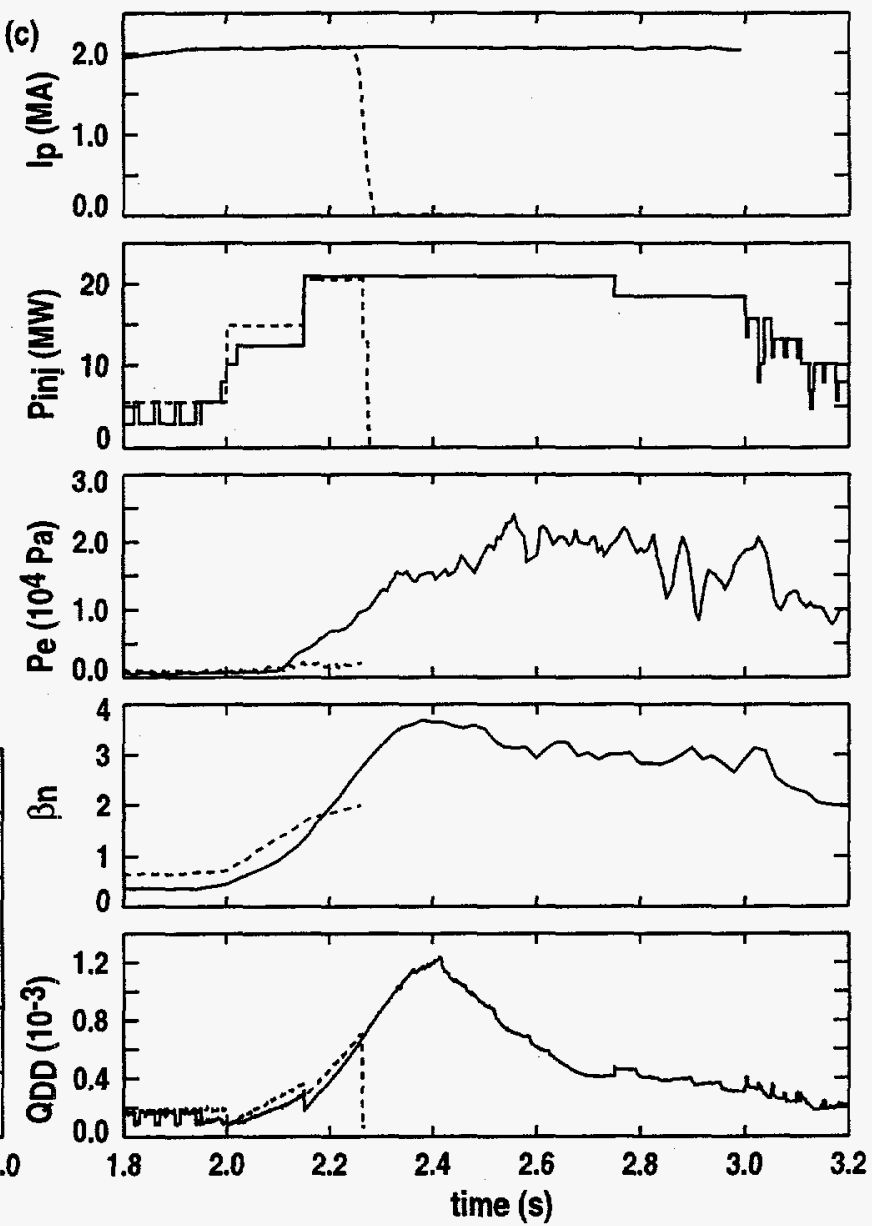

Fig. 2. Comparison of similar discharges with and without the stimulated $\mathrm{L}-\mathrm{H}$ transition. (a) Boundary shapes before and after the transition; (b) pressure profiles during L-and H-mode phases; (c) time evolution of the two discharges. 

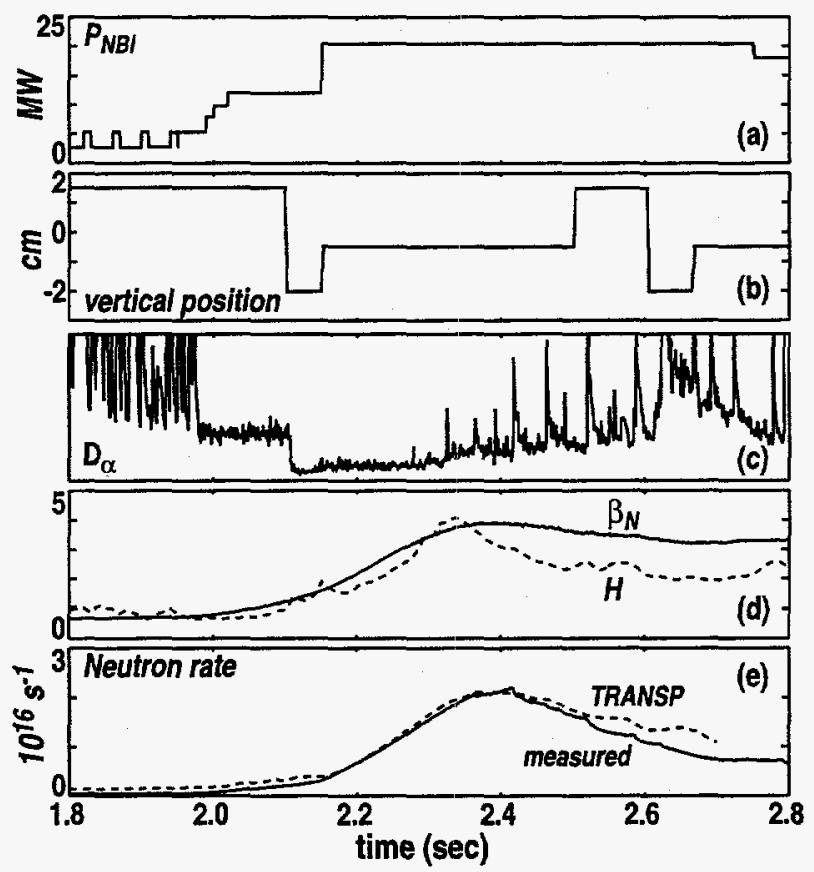

Fig. 3. Time evolution of a discharge with high fusion gain: (a) $P_{\mathrm{NBI}}$; (b) vertical position; (c) $\mathrm{D}_{\alpha}$ emission; (d) $\beta_{\mathrm{N}}$ and $H$ factor; (e) measured and calculated (TRANSP thermonuclear, beam-plasma and total) neutron rates. Shot $87937, I_{\mathrm{P}}=2.2 \mathrm{MA}$, $B_{\mathrm{T}}=2.1 \mathrm{~T}$. 


\section{TRANSPORT ANALYSIS}

Throughout the following discussion, the term "transport barrier" is used to describe a region of reduced transport extending over the entire region between the magnetic axis and the barrier location. Except where otherwise noted, where diffusivities are shown, we refer to the total diffusivity

$$
\chi_{\mathrm{i}, \mathrm{e}}=\chi_{\mathrm{i}, \mathrm{e}}^{\mathrm{total}} \equiv-\frac{q_{\mathrm{i}, \mathrm{e}}}{n_{\mathrm{i}, \mathrm{e}} \nabla T_{\mathrm{i}, \mathrm{e}}},
$$

for ions $\left(\chi_{\mathrm{i}}\right.$ or electrons $\left(\chi_{\mathrm{e}}\right)$. This formulation of the diffusivity avoids the difficulties of separating the conductive and convective heat loss terms. There is considerable uncertainty in this decomposition due to the difficulty of accurately determining the of the particle sources in the divertor configuration. Additionally, the value of the coefficient of the convective term is the subject of some controversy ${ }^{14}$ which is avoided by treating the data in this way. This diffusivity can be treated as an upper limit to the purely conductive diffusivity.

In each of the analyses below, the MHD equilibria were reconstructed using the EFIT equilibrium code ${ }^{15}$ including data from external magnetic measurements and motional Stark effect $^{16}$ (MSE). Significant radial electric field effects on the MSE data ${ }^{17}$ have been corrected for in this analysis. The radial electric field can approach $200 \mathrm{kV} / \mathrm{m}$ in the highest performance discharges. Measured profiles of electron density from Thomson scattering and $\mathrm{CO}_{2}$ laser interferometry, electron temperature from Thomson scattering and electron cyclotron emission, ion temperature from charge exchange recombination, impurity density from charge exchange recombination, plasma rotation from charge exchange recombination, and radiated power from bolometry, as well as results from the aforementioned equilibrium reconstructions were used as input to the TRANSP ${ }^{18}$ and ONETWO ${ }^{19}$ analysis codes.

\section{III.A. Internal transport barrier formation}

In shot $89943\left(I_{\mathrm{P}}=1.6 \mathrm{MA}, \beta_{\mathrm{T}}=2.1 \mathrm{~T}\right)$, a discharge with an $\mathrm{L}$-mode edge and a region of negative magnetic shear in the core (Fig. 4), a region of reduced transport appears in the core at $t \approx 0.65 \mathrm{~s}$, shortly after the initial application of $5 \mathrm{MW}$ of neutral beam power at $t \approx 0.35 \mathrm{~s}$. These conditions evolve slowly until the applied power is incremented to $7 \mathrm{MW}$ and the plasma current reaches its full value at $1.37 \mathrm{~s}$. After this time, the transport barrier region rapidly expands, with further reductions in both the electron and ion transport channels evident over the entire region $\rho<0.7$ (Fig. 5).

During this interval, both far infrared scattering (FIR, $k=2 \mathrm{~cm}^{-1}$ ) and beam emission spectroscopy (BES, $k \leq 2 \mathrm{~cm}^{-1}$ ) detect gradually decreasing levels of density fluctuations over a broad region of the plasma, with the ion diffusivity exhibiting a similar decrease (Fig. 4). The observation of decreased fluctuations in a region outside of the transport 

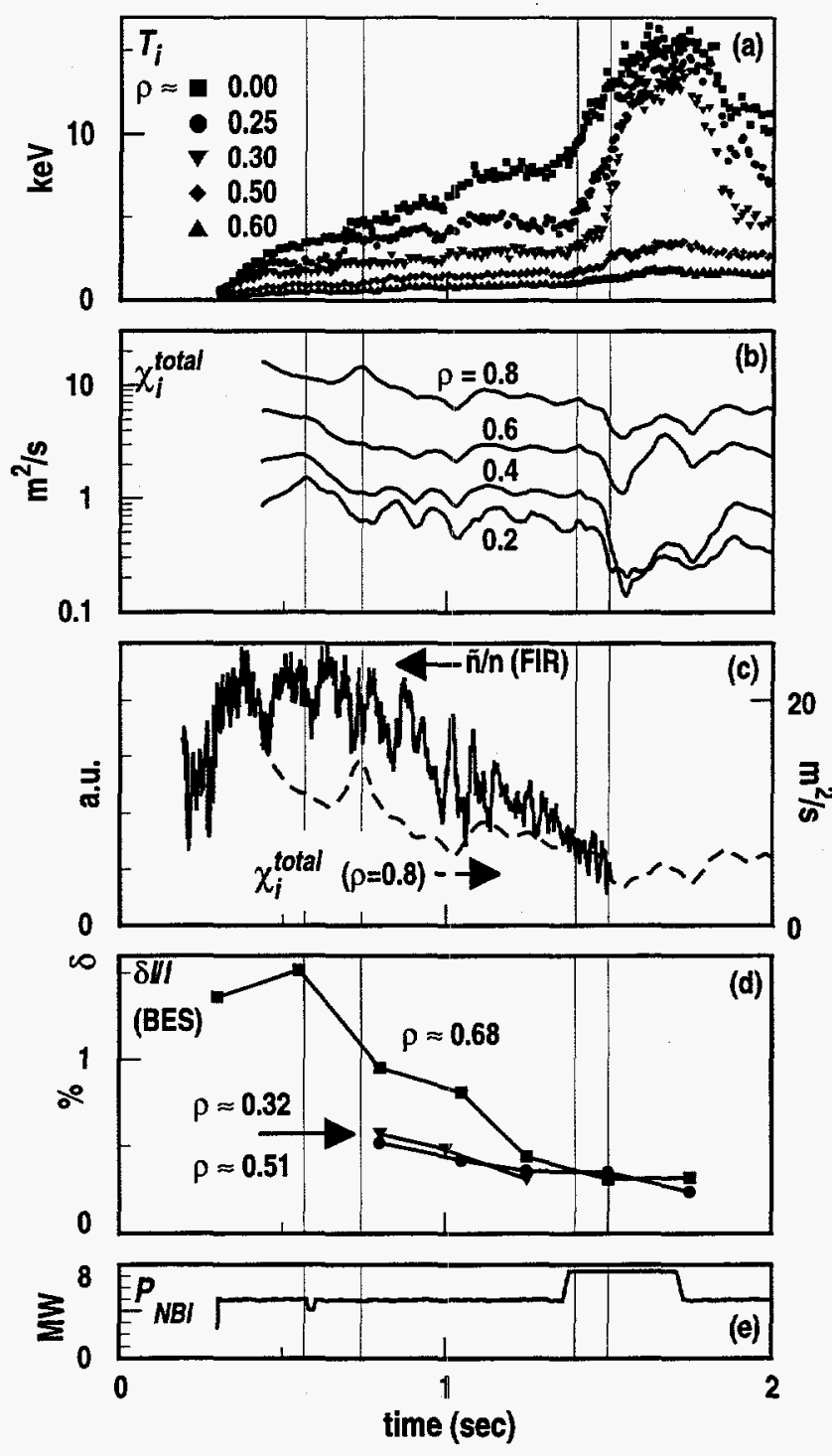

Fig 4. (a) Ion temperature at several different positions in the plasma indicates transport barrier growth starting at $0.7 \mathrm{~s}$ and increasing after the beam power steps up at $1.37 \mathrm{~s}$; (b) total ion diffusivity (shown on a logarithmic scale) calculated by TRANSP. Fluctuations measured by (c) FIR scattering (viewing the region $r / a=0.8 \pm 0.5$ ) and (d) BES indicate a slow, continuous drop in turbulence [with a similar decrease in the ion diffusivity, shown on a linear scale in (c)] rather than a fast drop at the transitions. (e) Neutral beam power. Shot $89943, I_{\mathrm{p}}=1.6 \mathrm{MA}, B_{\mathrm{T}}=2.1 \mathrm{~T}$, L-mode. The initial transport barrier formation, evidenced by a sudden increase in ion temperature at $\rho=0.25$ and a decrease in ion diffusivity in the same region, occurs betwen the first two marked timeslices, at approximately $t=0.65 \mathrm{~s}$. The marked timeslices at 1.4 and $1.5 \mathrm{~s}$, just prior to and during the rapid transport barrier growth phase, are examined in detail in Fig. 5.

barrier appears to be a common feature in discharges in DIII-D, and will be the subject of further study. The reduction in turbulence seen in the FIR scattering data at the transition after $1.37 \mathrm{~s}$ (Fig. 5) appears to be more a part of this general trend than a sudden event, however, it is possible some of the detail here was lost after the end of the FIR scattering data record 

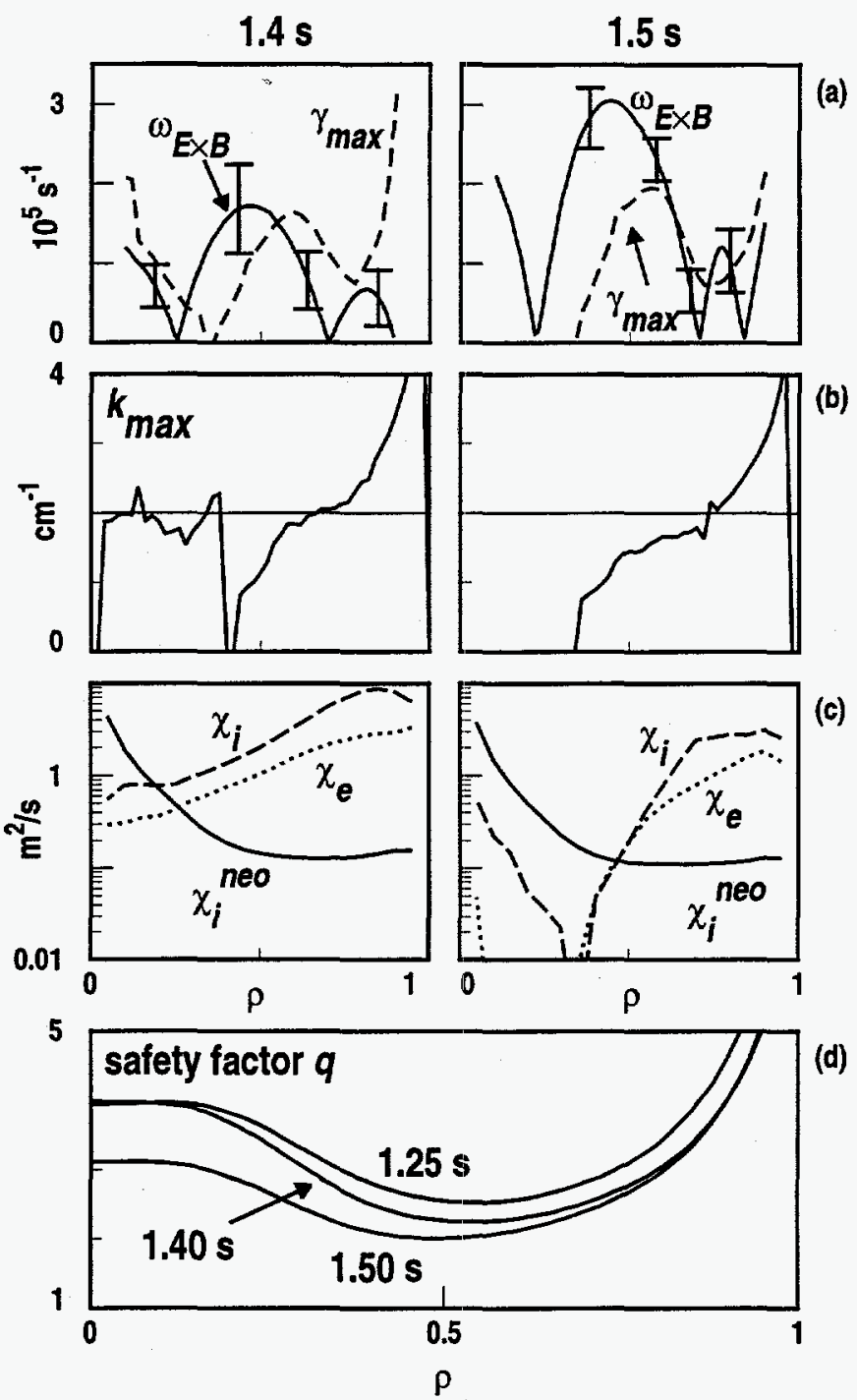

Fig. 5. (a) Shearing rate $\omega_{E \times B}$ and maximum calculated growth rate $\gamma_{\max }$ at 1.4 and $1.5 \mathrm{~s}$ indicate growth of the region where microturbulence is expected to be stabilized in the core; (b) $k_{\max }$, the wavenumber at which $\gamma_{\max }$ occurs; (c) both the ion and electron diffusivities decrease when $\omega_{E \times B}>\gamma_{\max }$; (d) safety factor profiles at several times during the discharge. Shot $89943, I_{\mathrm{p}}=1.6 \mathrm{MA}, B_{\mathrm{T}}=2.1 \mathrm{~T}, \mathrm{~L}$-mode.

(more rapid reductions are often seen in the FIR scattering data at higher beam power). The lack of a further decrease seen in the BES data may be due to the fact that the fluctuation spectrum has become dominated by Doppler broadening due to strong plasma rotation, and the signal can no longer be resolved (the BES diagnostic is currently being upgraded to alleviate this situation for future experiments).

The transport behavior in this discharge appears consistent with the paradigm of stabilization of microturbulence by $\vec{E} \times \vec{B}$ flow shear. ${ }^{20}$ The $\vec{E} \times \vec{B}$ shearing rate $\omega_{E \times B}$ is calculated from Eq. (2): 


$$
\omega_{E \times B}=\frac{\left(R B_{\theta}\right)^{2}}{B} \frac{\partial}{\partial \psi}\left(\frac{E_{r}}{R B_{\theta}}\right),
$$

with the radial electric field given by radial force balance:

$$
E_{r}=\left(Z_{\mathrm{i}} e n_{\mathrm{i}}\right)^{-1} \nabla p_{\mathrm{i}}-v_{\theta \mathrm{i}} B_{\varphi}+v_{\varphi \mathrm{i}} B_{\theta} .
$$

The impurity ion velocity and pressure is determined from charge exchange recombination, and the magnetic equilibrium from the reconstruction discussed above.

This shearing rate can be compared to theory-based predictions of turbulence growth rates made using a 3-D ballooning mode linear gyrokinetic stability code (GKS $\left.{ }^{21}\right)$ in the electrostatic limit. In these calculations, the maximum growth rate $\gamma_{\max }$ is computed as the larger of the growth rates of the ion temperature gradient (ITG) and dissipative trapped electron modes (TEM). A comparison of the shearing rates and calculated growth rates is shown in Fig. 5. Although the theories do not specify a hard threshold for transport reduction at $\omega_{E \times B} \equiv \gamma_{\max }$, in practice we often observe sharp decreases in transport when this condition is exceeded in DIII-D. Prior to the transition, at $t \approx 1.4 \mathrm{~s}$, the $\vec{E} \times \vec{B}$ shearing rate is insufficient to overcome the calculated growth rates over most of the plasma. The relatively narrow region where $\omega_{E \times B}$ slightly exceeds $\gamma_{\max }$ coincides with the region in which the transport barrier began to form at $0.7 \mathrm{~s}$. Note that the feature in the calculated growth rates at $\rho<0.4$ at this time appears to be due to TEM modes, while the outer feature is consistent with ITG modes.

After the transition, at $t \approx 1.5 \mathrm{~s}$, the TEM feature previously seen has completely vanished due to increased separation of the ion and electron temperatures $T_{\mathrm{i}}(0) / T_{\mathrm{e}}(0)$ has increased from slightly above 2 prior to the transition to about 3 at this time. The growth rates for the ITG mode are still finite, but now significantly smaller than the newly increased $\vec{E} \times \vec{B}$ shearing rate over much of the region $0.4<\rho<0.7$, corresponding to the region of further reduced transport.

Note that at this time, ion transport appears to be reduced below the theoretical "irreducible minimum" Chang-Hinton neoclassical ${ }^{3}$ value for $\rho<0.45$. This apparent discrepancy may be explained by considering that these plasmas violate the basic assumption of small ion orbits made in developing the neoclassical theory in the central region. Although work has been done on extending the theory for such cases ${ }^{22,23}$ as these, no such correction has yet been applied to this analysis.

\section{III.B. Extension of the transport barrier to the entire plasma}

As shown above, plasmas with an L-mode edge and weak negative magnetic shear in the core are observed to exhibit a region of reduced transport in the core. These plasmas can exhibit very high performance compared to previous experiments in DIII-D, ${ }^{10}$ but invariably disrupt 
at high power. ${ }^{2}$ As discussed in Section II, the disruption can be avoided by stimulating an $\mathrm{L}-\mathrm{H}$ transition shortly before the disruption would occur.

Figure 6 shows a pair of similar discharges which undergo an $\mathrm{L}-\mathrm{H}$ transition at $t=2.106 \mathrm{~s}$ and continue to achieve high performance (the difference between these discharges will be discussed in Section III.C). For this discussion, we will concentrate on shot 87937. Figure 7 shows profiles shortly before the $\mathrm{H}$-mode transition, and later during the ELM-free phase. The ion temperature and rotation profiles, which were peaked in the L-mode phase, become broadened. The total ion diffusivity [shown to indicate an upper limit to the diffusivity, Eq. (1)] drops to zero (TRANSP indicates slightly negative values, but well within any reasonable error estimate of zero) in the outer half of the plasma during $\mathrm{H}$-mode, while remaining near, but still above neoclassical in the core. The purely conductive ion diffusivity, already near neoclassical in the core during $\mathrm{L}$-mode, decreases to essentially zero throughout the plasma in $\mathrm{H}$-mode. Transport calculations indicate that at this time there is no significant conducted power flux in the ion channel anywhere in the plasma.
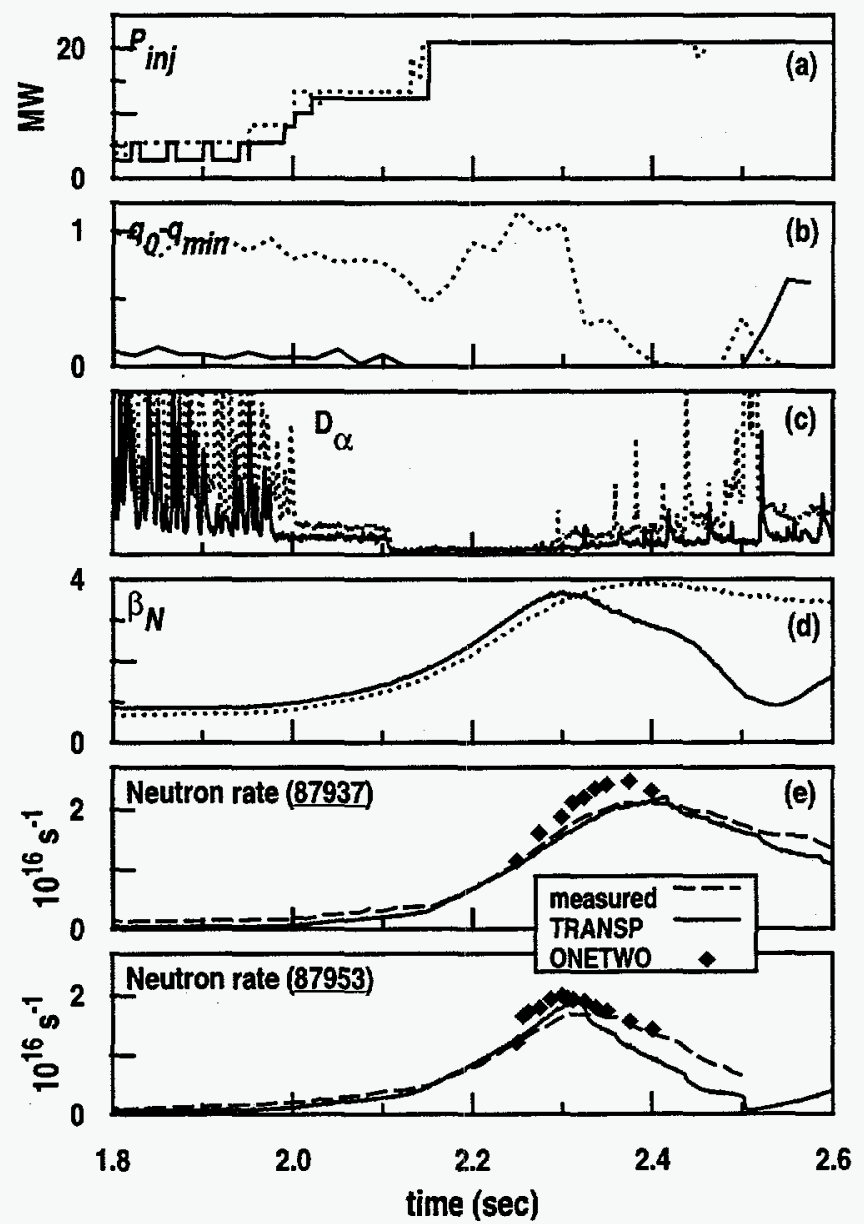

Fig. 6. Time evolution of a pair of $\mathrm{H}$-mode discharges with weak (87937) and negative (87953) central magnetic shear. (a) $P_{\mathrm{NBI}}$; (b) $q(0)-q_{\min }$; (c) $\mathrm{D}_{\alpha}$ emission; (d) $\beta_{\mathrm{N}}$; and $H$ factor; (e) measured and calculated (TRANSP) neutron rates. $l_{\mathrm{P}}=2.2 \mathrm{MA}$, $B_{\mathrm{T}}=2.1 \mathrm{~T}, P_{\mathrm{NBI}}=20.4 \mathrm{MW}, t_{\mathrm{L}-\mathrm{H}}=2.106 \mathrm{~s}$. 

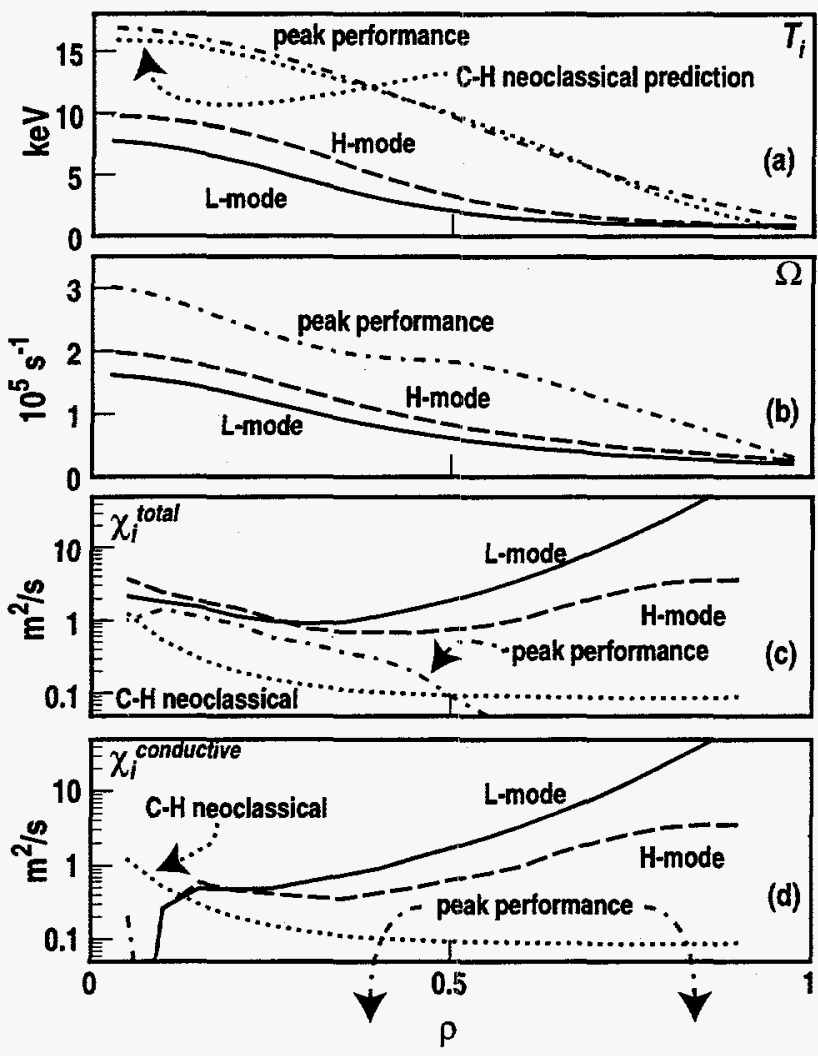

Fig. 7. (a) Ion temperature, (b) rotation, (c) total, and (d) purely conductive diffusivity profiles at the beginning of the high power phase, shortly before the $\mathrm{L}-\mathrm{H}$ transition and during the ELM-free H-mode phase. Shot 87937, $I_{\mathrm{P}}=2.2 \mathrm{MA}, B_{\mathrm{T}}=2.1 \mathrm{~T}$, $P_{\mathrm{NBI}}=20.4 \mathrm{MW}, t_{\mathrm{L}-\mathrm{H}}=2.106 \mathrm{~s}$.

As in the L-mode case of the previous section, these results are consistent with the paradigm of stabilization of microturbulence by $\vec{E} \times \vec{B}$ flow shear. Comparison of the calculated growth rates to the shearing rate show that after the $\mathrm{L}-\mathrm{H}$ transition, $\omega_{E \times B}>\gamma_{\max }$ everywhere in the plasma (Fig. 8b). Based on this observation, one might expect microturbulence to be suppressed everywhere in the plasma. Indeed, FIR scattering indicates that prior to the $\mathrm{L}-\mathrm{H}$ transition in these discharges, core turbulence has already been reduced to undetectably small levels. The remaining fluctuations vanish after the $\mathrm{L}-\mathrm{H}$ transition. ${ }^{24}$

\section{III.C. Dependence of transport on magnetic shear}

The two discharges shown in Fig. 6 are similar in nearly every respect except that the target conditions, at the beginning of the high neutral beam power phase of shot 87953 , were developed with slightly higher beam power in the early phase, resulting in a target plasma with negative central magnetic shear [ $S=(2 V / q) d q / d V$, where $V$ is the volume enclosed by a flux surface and $q$ is the safety factor]. Shot 87937 , with less power in the early phase, produces a target with almost no shear in the center (Fig. 8). Although there are clearly differences in the stability of these two discharges, ${ }^{2}$ the diffusivities are quite similar. Each of 

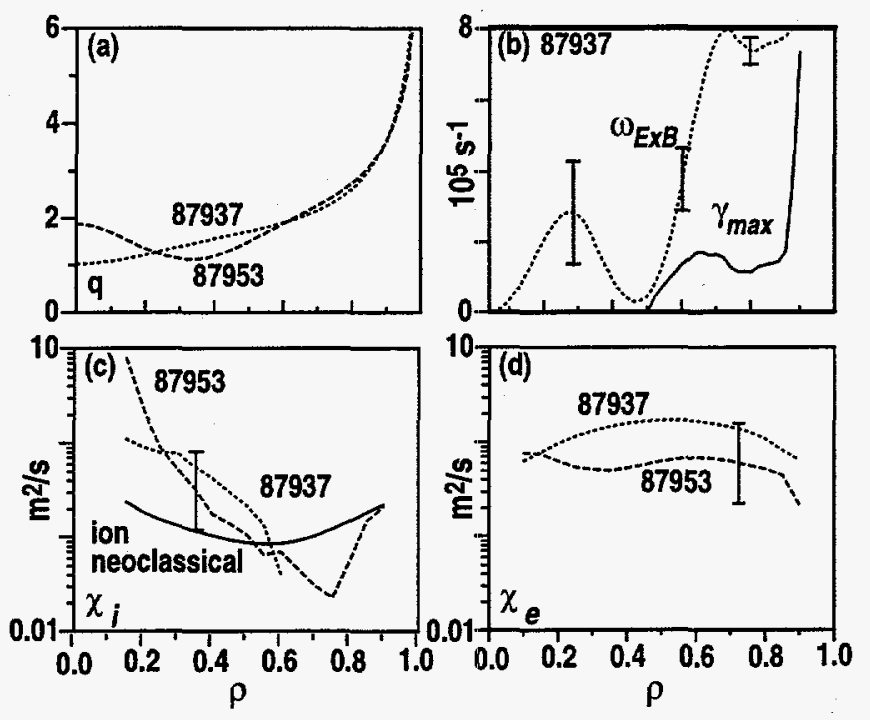

Fig. 8. (a) H-mode edge discharges with negative magnetic shear (87953) and weakly positive magnetic shear (87937) in the core. (b) The Doppler shift shearing rate $\omega_{E \times B}$ is greater than the turbulence growth rate $\gamma_{\max }$ at all radii for the discharge with weakly positive shear (similar results are obtained for the discharge with negative central shear). (c, d) Dependence of ion and electron diffusivity on magnetic shear is not indicated. $I_{\mathrm{P}}=2.2 \mathrm{MA}, B_{\mathrm{T}}=2.1 \mathrm{~T}, P_{\mathrm{NBI}}=20.4 \mathrm{MW}$.

these discharges is predicted by the procedure given above to be stabilized against microturbulence throughout the entire plasma.

The $\mathrm{L}$-mode discharges contrast the behavior of the $\mathrm{H}$-mode discharges. A comparison of a pair of L-mode discharges with differing amounts of magnetic shear in the core (Fig. 9) shows that in this case, the plasma with more strongly reversed central shear exhibits a lower central diffusivity. Whether this is a consequence of lower neoclassical levels in this discharge is as yet unknown, since we do not yet have an accurate means of determining the neoclassical values in this region (see discussion in Section III.A). Differences in $\vec{E} \times \vec{B}$ flow shear alone are insufficient to explain this difference, since both discharges are calculated to have nearly identical levels of flow shear.

None of this should be taken to negate the importance of shear in the formation of these discharges, however. The target conditions, prior to the application of high neutral beam power, are calculated to be MHD unstable with strongly positive central magnetic shear. With weak or negative shear, however, the core region can access the second stable regime for ballooning modes, allowing the central pressure gradients to increase to the levels necessary for significant $\vec{E} \times \vec{B}$ flow shear to occur. 

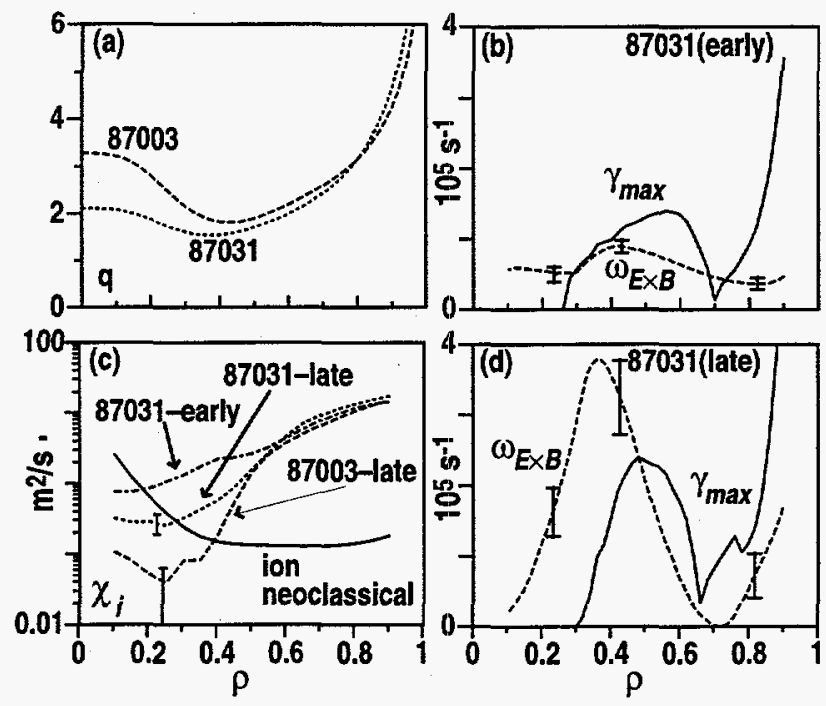

Fig. 9. (a) L-mode edge discharges with strongly (87003) and weakly (87031) negative central magnetic shear (b) During the early formation of the transport barrier the turbulence growth rate $\gamma_{\max }$ exceeds the Doppler shift shear rate $\omega_{E \times B}$. (c) $\chi_{\mathrm{i}}$ is reduced from before (early at $5 \mathrm{MW}$ ) the transport barrier to after (late at $10 \mathrm{MW}$ ) the transport barrier formation. For fixed conditions $\chi_{\mathrm{i}}$ is reduced for larger magnetic shear. (d) After the transport barrier formation $\gamma_{\max }<\omega_{E \times B}$ in the region of reduced ion transport. 


\section{EXTRAPOLATION TO DT OPERATION}

The highest fusion gain discharge (87977, see Table I and Fig. 3) was used as the basis for calculations of the performance of an equivalent discharge fueled with a 50:50 deuteriumtritium mix at the same level of neutral beam power. In this computational modeling, the density, temperature, and rotation profiles were all held constant in the DT plasma as measured in the DD plasma. The DT mixture was adjusted by varying the relative concentrations of deuterium and tritium in the working gas and neutral beam. Due to the relatively poor penetration of the tritium beams, over half of the neutral beam power must be applied from tritium beams, but with the proper choice of the initial mixture, a steady core mixture can be obtained [Fig. 10(a)]. Starting the discharge in pure deuterium, with neutral beams being the sole source of tritium, results in low DT gain, since these discharges are too transitory for the beams to replace half of the deuterium with tritium before the high performance phase terminates.

Table I. Parameters of highest performance H-mode discharges with weak central magnetic shear.

\begin{tabular}{lll}
\hline \hline & 87977 & 87980 \\
\hline Plasma current $I_{\mathrm{P}}$ & $2.2 \mathrm{MA}$ & $2.4 \mathrm{MA}$ \\
Toroidal magnetic field $B_{\mathrm{T}}$ & $2.1 \mathrm{~T}$ & $2.1 \mathrm{~T}$ \\
Neutral beam power $P_{\mathrm{NBI}}$ & $17.5 \mathrm{MW}$ & $20.2 \mathrm{MW}$ \\
Stored energy $W_{\mathrm{MHD}}$ & $4.2 \mathrm{MJ}$ & $4.5 \mathrm{MJ}$ \\
Toroidal beta $\beta_{\mathrm{T}}$ & $6.8 \%$ & $7.2 \%$ \\
Normalized $\beta_{\mathrm{N}}$ & $4.0 \%-\mathrm{m}-\mathrm{T} / \mathrm{MA}$ & $3.9 \%-\mathrm{m}-\mathrm{T} / \mathrm{MA}$ \\
Confinement time $\tau_{\mathrm{B}}$ & $0.5 \mathrm{~s}$ & $0.4 \mathrm{~s}$ \\
Normalized confinement time $H$ & 4.0 & 3.5 \\
DD neutron rate $S_{\mathrm{N}}$ & $2.2 \times 10^{16} \mathrm{~s}^{-1}$ & $2.4 \times 10^{16} \mathrm{~s}^{-1}$ \\
Fusion power $P_{\mathrm{DD}}$ & $26 \mathrm{~kW}$ & $28 \mathrm{~kW}$ \\
Equivalent fusion power $P_{\mathrm{DD}}^{\text {equivalent }}$ & $5.8 \mathrm{MW}$ & $6.0 \mathrm{MW}$ \\
Fusion power efficiency $Q_{\mathrm{DD}}$ & $1.5 \times 10^{-3}$ & $1.4 \times 10^{-3}$ \\
Equivalent DT fusion power efficiency $Q_{\mathrm{DT}}^{\text {equivalent }}$ & 0.32 & 0.30 \\
\hline \hline
\end{tabular}

Under these conditions, the predicted DT fusion power $P_{\mathrm{DT}}$ is calculated to be about 215 times greater than the calculated $P_{\mathrm{DT}}$ (Fig. 10). Applying this factor to the measured fusion gain, using the measured rather than the calculated value of $P_{\mathrm{DD}}$ to eliminate systematic errors, of the highest yield DD discharge $\left(Q_{\mathrm{DD}}=1.5 \times 10^{3}\right)$ in DIII-D results in $Q_{\mathrm{DT}}^{\text {equivalent }} \approx 0.32$ and $P_{\mathrm{DT}}^{\text {equivalent }} \approx 6 \mathrm{MW}$. The calculated multiplier value of 215 is a robust result that has survived several reanalyses of this discharge. Similar values have been calculated for several other discharges as well. Comparable multipliers have also been calculated for plasmas in the Joint European Torus ( JET) ${ }^{25}$ with similar parameters. ${ }^{26}$ 

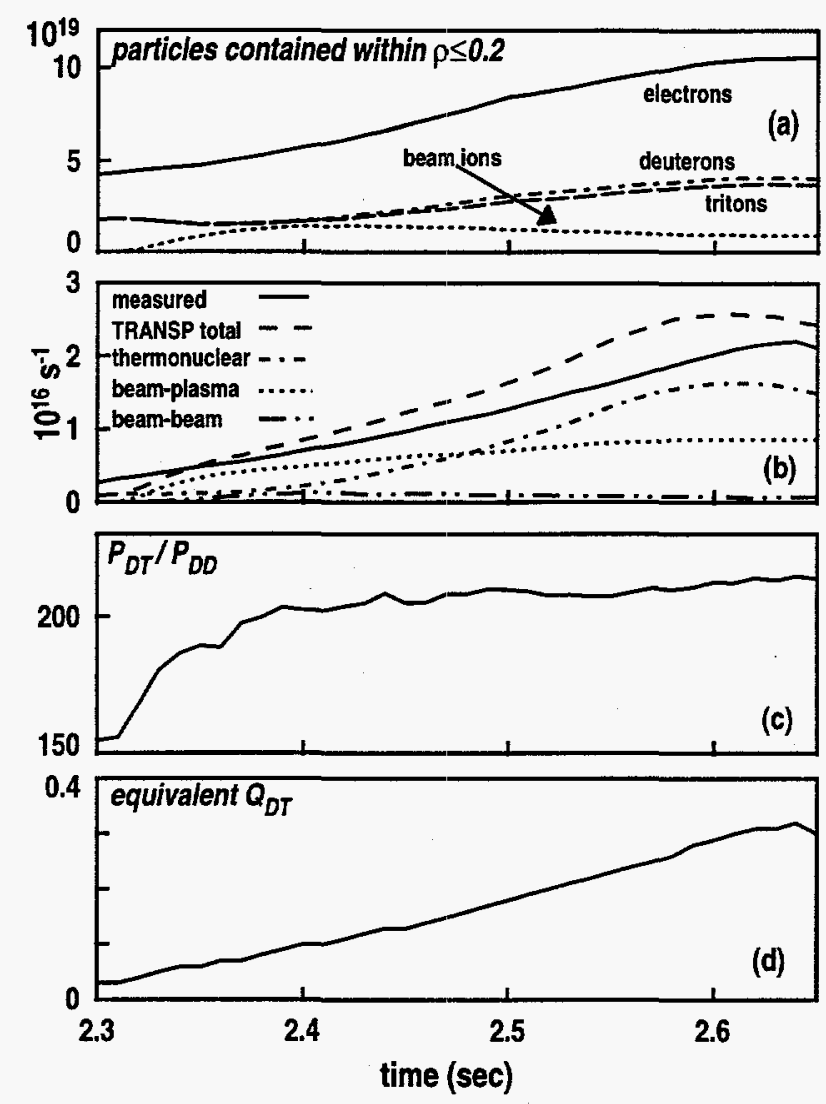

Fig. 10. (a) Central particle densities calculated in a discharge modeled after 87977 with a 50:50 deuterium-tritium mix; (b) Neutron rates from the same discharge; (c) The ratio of DT to DD fusion power $P_{\mathrm{DT}} / P_{\mathrm{DD}}$ calculated by TRANSP based on (delete a) his run and a second "analysis mode" run directly modeling the same discharge; (d) $Q_{\mathrm{DT}}^{\text {equivalent }}$ versus time.

We note that the ratio $P_{\mathrm{DT}} / P_{\mathrm{DD}}$ is higher than published predicted multipliers for the Tokamak Fusion Test Reactor (TFTR). ${ }^{27}$ Supershots computed via a similar procedure. ${ }^{28}$ This is not unreasonable given the differences between these discharges and Supershots. Although the cross sections for DT fusion reactions are larger under TFTR Supershot conditions, where $T_{\mathrm{i}}(0) \approx 35 \mathrm{keV}$ and $E_{\mathrm{NBI}}=110 \mathrm{kV}$, than in DIII-D discharges with $T_{\mathrm{i}}(0) \approx 18 \mathrm{keV}$ and $E_{\mathrm{NBI}} \approx 80 \mathrm{kV}$, the ratios of the DT cross sections to the DD cross sections are smaller. The higher central ion temperatures in Supershots result in a considerably lower ratio $\langle\sigma v\rangle_{\mathrm{DT}} /\langle\sigma v\rangle_{\mathrm{DD}}$ (by about $25 \%$ on axis), and therefore of the thermonuclear reactivity multiplier. The higher neutral beam voltages in TFTR lead to a reduction of about $10 \%$ in the ratio $\sigma_{\mathrm{DT}} / \sigma_{\mathrm{DD}}$ and therefore of the beam-plasma reactivity multiplier. Also, the fractional contributions of thermonuclear and beam-target fusion reactions is very different for the two regimes, with Supershots having higher fast ion populations.

Projecting fusion performance from a deuterium discharge to a DT is not without uncertainty. In DT Supershots in TFTR, measured fusion performance has been lower than calculations based on similar deuterium discharges would indicate. ${ }^{29}$ However, simulations based on 
deuterium hot-ion $\mathrm{H}$-mode discharges in JET accurately predict the reactivity of comparable discharges with small amounts of tritium added. ${ }^{26}$ These plasmas, with broad temperature and density profiles and central ion temperatures of about $20 \mathrm{keV}$, are similar in many respects to the DIII-D discharges. We cannot be certain, of course, that the performance in JET will continue to behave as predicted with higher concentrations of tritium. The experience with other devices serves most of all to point out the uncertainty in such calculations; nevertheless, this is a valuable exercise in benchmarking the progress made in these experiments. 


\section{SUMMARY AND CONCLUSIONS}

By combining the favorable properties of discharges with weak or negative central magnetic shear in the core with the enhanced edge of the $\mathrm{H}$-mode, we have produced plasmas which obtain levels of performance significantly above that previously achieved in DIII-D. In order to achieve this, a method of obtaining a stimulated $\mathrm{L}-\mathrm{H}$ transition by controlling the plasma position in a nominally double-null divertor geometry was developed. Following the $\mathrm{L}-\mathrm{H}$ transition, a high performance plasma which would otherwise have disrupted continues to evolve with broadened profiles to still higher levels of stored energy, confinement and reactivity.

These discharges build on an L-mode target plasma which exhibits neoclassical levels of transport in their core. This transport, near the (omit "irreducible minimum") level predicted by neoclassical theory, is made possible by nearly complete stabilization of microturbulence in this region by sheared flows in the plasma, and is consistent with theoretical predictions. As the region of reduced transport develops, density fluctuations measured by both FIR scattering and BES are seen to decrease, with unmeasurably small levels of turbulence in the core when high power is applied.

After the L-H transition, the profiles broaden, and the ion transport over the entire cross section of the discharge becomes comparable to neoclassical values. These plasmas continue to evolve until the high performance phase terminates with high levels of MHD and density near the boundary. The discharges typically continue in an $\mathrm{H}$-mode state with edge located modes (ELMs).

The discharge with the highest fusion gain reached $Q_{\mathrm{DD}}=1.5 \times 10^{-3}$ and produced $26 \mathrm{~kW}$ of DD fusion power. Projections of the power that could be produced by replacing half of the deuterium in the discharge with tritium indicate a factor of 215 increase in output power, and project that a device with similar parameters to DIII-D could obtain fusion power gain $Q_{\mathrm{DT}} \approx 0.32$.

During the past year, this effort has resulted in a factor of two increase in fusion power produced in DIII-D. These experiments utilize rather simple profile control tools: early neutral beam heating to set up the current profile, and triggered $\mathrm{L}-\mathrm{H}$ transitions to broaden the pressure profile. With future advances in profile control tools, such as fast wave rf and electron cyclotron heating, we hope to be able to not only further improve performance, but to sustain the high performance phase for longer periods of time, as well. With such tools, this regime holds great promise for future accomplishments. 


\section{ACKNOWLEDGMENTS}

The authors would like to acknowledge the assistance of D.C. McCune, R.V. Budny, R.M. Wieland, and T. Terpstra of the Princeton Plasma Physics Laboratory for their assistance in using the TRANSP code.

This is a report of research supported by the U.S. Department of Energy under Contract Nos. DE-AC03-89ER51114, W-7405-ENG-48, and DE-AC05-96OR22464, and Grant Nos. DE-FG02-89ER53297, DE-FG03-86ER-53266, and DE-FG02-92ER54139. 


\section{REFERENCES}

1J.L. Luxon, R. Anderson, F. Batty, C.B. Baxi, G. Bramson, N.H. Brooks, B. Brown, B. Burley, K.H. Burrell, R. Callis, G. Campbell, T.N. Carlstrom, A.P. Colleraine, J. Cummings, L. Davis, J.C. DeBoo, S. Ejima, R. Evanko, H. Fukumoto, R. Gallix, J. Gilleland, T. Glad, P. Gohil, A. Gootgeld, R.J. Groebner, S. Hanai, J. Haskovec, E. Heckman, M. Heilberger, F.J. Helton, N. Hosogane, C.-L. Hsieh, G.L. Jackson, G. Jahns, G. Janeschitz, E. Johnson, A.G. Kellman, J.S. Kim, J. Kohli, A. Langhorn, L.L. Lao, P. Lee, S. Lightner, J. Lohr, M.A. Mahdavi, M. Mayberry, B. McHarg, T. McKelvey, R. Miller, C.P. Moeller, D. Moore, A. Nerem, P. Noll, T. Ohkawa, N. Ohyabu, T.H. Osborne, D.O. Overskei, P.I. Petersen, T.W. Petrie, J. Phillips, R. Prater, J. Rawls, E.E. Reis, D. Remsen, P. Riedy, P. Rock, K. Schaubel, D.P. Schissel, J.T. Scoville, J.P. Smith, Jr., P. Smith, T. Smith, R.T. Snider, R.D. Stambaugh, R. Stav, H. St. John, R.E. Stockdale, E.J. Strait, R. Street, T.S. Taylor, J. Tooker, M. Tupper, S.K. Wong, and S. Yamaguchi, in Plasma Physics and Controlled Nuclear Fusion Research, 1986 (International Atomic Energy Agency, Vienna, 1987), Vol. I, p. 159.

2E.J. Strait, T.A. Casper, M.S. Chu, J.R. Ferron, A. Garofalo, C.M. Greenfield, R.J. La Haye, L.L. Lao, E.A. Lazarus, R.L. Miller, G.A. Navratil, C. Ren, B.W. Rice, I. Semenov, A.C.C. Sips, F.X. Söldner, B.W. Stallard, T.S. Taylor, and A.D. Turnbull, "Stability of Negative Central Magnetic Shear Discharges in the DIII-D Tokamak," this conference.

${ }^{3}$ C.S. Chang, F.L. Hinton, Phys. Fluids 29, 3314 (1986).

${ }^{4}$ E.J. Strait, L.L. Lao, M.E. Mauel, B.W. Rice, T.S. Taylor, K.H. Burrell, M.S. Chu, E.A. Lazarus, T.H. Osborne, S.J. Thompson, A.D. Turnbull, Phys. Rev. Lett. 75, 4421 (1995).

${ }^{5}$ B.W. Rice, K.H. Burrell, L.L. Lao, G. Navratil, B.W. Stallard, E.J. Strait, T.S. Taylor, M.E. Austin, T.A. Casper, M.S. Chu, C.B. Forest, P. Gohil, R.J. Groebner, W.W. Heidbrink, A.W. Hyatt, H. Ikezi, R.J. La Haye, E.A. Lazarus, Y.R. Lin-Liu, M.E. Mauel, W.H. Meyer, C.L. Rettig, D.P. Schissel, H.E. St. John, P.L. Taylor, A.D. Turnbull, and the DIII-D Team, Phys. Plasmas 3, 1983 (1996).

6L.L. Lao, K.H. Burrell, T.S. Casper, V.S. Chan, M.S. Chu, J.C. DeBoo, E.J. Doyle, R.D. Durst, C.B. Forest, C.M. Greenfield, R.J. Groebner, F.L. Hinton, Y. Kawano, E.A. Lazarus, Y.R. Lin-Liu, M.E. Mauel, W.H. Meyer, R.L. Miller, G.A. Navratil, T.H. Osborne, Q. Peng, C.L. Rettig, G. Rewoldt, T.L. Rhodes, B.W. Rice, D.P. Schissel, B.W. Stallard, E.J. Strait, W.M. Tang, T.S. Taylor, A.D. Turnbull, R.E. Waltz, and the DIII-D Team, Phys. Plasmas 3, 1951 (1996). 
${ }^{7}$ E.A. Lazarus, G.A. Navratil, C.M. Greenfield, E.J. Strait, M.E. Austin, K.H. Burrell, T.A. Casper, D.R. Baker, J.C. DeBoo, E.J. Doyle, R. Durst, J.R. Ferron, C.B. Forest, P. Gohil, R.J. Groebner, W.W. Heidbrink, R.-M. Hong, W.A. Houlberg, A.W. Howald, C.-L. Hsieh, A.W. Hyatt, G.L. Jackson, J. Kim, L.L. Lao, C.J. Lasnier, A.W. Leonard, J. Lohr, R.J. La Haye, R. Maingi, R.L. Miller, M. Murakami, T.H. Osborne, L.J. Perkins, C.C. Petty, C.L. Rettig, T.L. Rhodes, B.W. Rice, S.A. Sabbagh, D.P. Schissel, J.T. Scoville, R.T. Snider, G.M. Staebler, B.W. Stallard, R.D. Stambaugh, H.E. St. John, R.E. Stockdale, P.L. Taylor, D.M. Thomas, A.D. Turnbull, M.R. Wade, R. Wood, D. Whyte, Phys. Rev. Lett. 77, 2714 (1996).

${ }^{8}$ P. N. Yushmanov, T. Takizuka, K.S. Riedel, O.J.W.F. Kardaun, J.G. Cordey, S.M. Kaye, D.E. Post, Nucl. Fusion 30, 1999 (1990).

${ }^{9}$ C.B. Forest, S.C. Chiu, J.S. deGrassie, H. Ikezi, C.C. Petty, R.I. Pinsker, R. Prater, D.B. Batchelor, F.W. Baity, E.F. Jaeger, M. Murakami, J.H. Lee, M. Porkolab, Bull. Am. Phys. Soc. 41, 1387 (1996).

${ }^{10}$ E.A. Lazarus, A.W. Hyatt, T.H. Osborne, S.E. Attenberger, M.E. Austin, K.H. Burrell, T.A. Casper, M.S. Chu, J.W. Cuthbertson, E.J. Doyle, P. Gohil, J.M. Greene, C.M. Greenfield, R.J. Groebner, W.A. Houlberg, C.-L. Hsieh, G.L. Jackson, J. Kim, S. Konoshima, L.L. Lao, C.J. Lasnier, A.W. Leonard, S.I. Lippmann, M.A. Mahdavi, R. Maingi, R.A. Moyer, C.L. Rettig, B.W. Rice, M.J. Schaffer, D.P. Schissel, R.T. Snider, R.D. Stambaugh, R.E. Stockdale, T.S. Taylor, A.D. Turnbull, M.R. Wade, R. Wood, D. Wròblewski, in Plasma Physics and Controlled Nuclear Fusion Research, 1994 (International Atomic Energy Agency, Vienna, 1995), Vol. 1, p. 609.

${ }^{11}$ A.D. Turnbull, M.S. Chu, T.S. Taylor, T.A. Casper, J.M. Greene, C.M. Greenfield, R.J. La Haye, L.L. Lao, B.J. Lee, R.L. Miller, C. Ren, C.L. Rettig, T.L. Rhodes, B.W. Rice, O. Sauter, E.J. Strait, K. Tritz, in Plasma Physics and Controlled Nuclear Fusion Research (Proc. 16th Int. Conf., Montréal, 1996) (International Atomic Energy Agency, Vienna, in press), Paper F1-CN-64/DP-1.

12T.S. Taylor, A.D. Turnbull, L.L. Lao, Bull. Am. Phys. Soc. 40, 1786 (1995).

${ }^{13}$ R.J. Groebner, Phys. Fluids B 5, 2343 (1993).

${ }^{14}$ M.C. Zarnstorff, S.D. Scott. C.W. Barnes, R. Bell, C.E. Bush, Z. Chang, D. Ernst, R.J. Fonck, L.C. Johnson, E. Mazzucato, R. Nazikian, S.F. Paul, J. Schivell, E. Synakowski, H. Adler, M.G. Bell, R.V. Budny, E.D. Fredreickson, B. Grek, A.C. Janos, D.W. Johnson, D.C. McCune, H.K. Park, A.T. Ramsey, M.H. Redi, G. Taylor, M.E. Thompson, R. Wieland, in Plasma Physics and Controlled Nuclear Fusion Research, 1994 (International Atomic Energy Agency, Vienna, 1995), Vol. 1, p. 183. 
${ }^{15}$ L.L. Lao, J.R. Ferron, R.J. Groebner, W. Howl, H. St. John, E.J. Strait, T.S. Taylor, Nucl. Fusion 30, 1035 (1990).

16D. Wròblewski, L.L. Lao, Rev. Sci. Instrum. 63, 5140 (1992).

${ }^{17}$ B.W. Rice, K.H. Burrell, L.L. Lao, "Effect of Plasma Radial Electric Field on Motional Stark Effect Measurements and Equilibrium Reconstruction," General Atomics Report GA-A22480, submitted to Nucl. Fusion.

${ }^{18}$ R.J. Hawryluk, in Proceedings of the Course in Physics of Plasmas Close to Thermonuclear Conditions, Varenna, 1979 (Commission of the European Communities, Brussels, 1980), Vol. I, p. 19.

${ }^{19}$ See National Technical Information Service Document GA-A16178 (W.W. Pfeiffer, R.H. Davidson, R.L. Miller, R.E. Waltz, "ONETWO: A computer code for modeling plasma transport in tokamaks," General Atomics Report GA-A16178, 1980). Copies may be ordered from the National Technical Information Service, Springfield, Virginia 22161.

${ }^{20}$ T.S. Hahm, K.H. Burrell, Phys. Plasmas 2, 1648 (1995).

${ }^{21}$ M. Kotchenreuther, Bull. Am. Phys. Soc. 37, 1432 (1992).

${ }^{22}$ T.S. Hahm, M. Artun, M.A. Beer, G.W. Hammett, W.W. Lee, X. Li, Z. Lin, H.E. Mynick, S.E. Parker, G. Rewoldt, W.M. Tang, in Plasma Physics and Controlled Nuclear Fusion Research (Proc. 16th Int. Conf., Montréal, 1996) (International Atomic Energy Agency, Vienna, in press), Paper F1-CN-64/D1-2.

${ }^{23}$ F. Hinton, Bull. Am. Phys. Soc. 41, 1394 (1996). Paper 2Q11.

${ }^{24}$ C.L. Rettig, E.J. Doyle, T.L. Rhodes, W.A. Peebles, K.H. Burrell, C.M. Greenfield, R.J. Fonck, B.W. Rice, E.A. Lazarus, Bull. Am. Phys. Soc. 41, 1387 (1996). Paper $2 \mathrm{~F} 05$.

25P.-H. Rebut, R.J. Bickerton, B.E. Keen, Nucl. Fusion 25, 1011 (1985).

26B. Balet, P.M. Stubberfield, D. Borba, J.G. Cordey, N. Deliyanakis, C.M. Greenfield, T.T.C. Jones, R. König, F.B. Marcus, M.F. Nave, D.P. O'Brien, F. Porcelli, G. Sadler, K. Thomsen, M. von Hellermann, Nucl. Fusion 33, 1345 (1993).

27D. Meade and the TFTR Group, in Plasma Physics and Controlled Nuclear Fusion Research, 1990 (International Atomic Energy Agency, Vienna, 1991), Vol. I, p. 9.

${ }^{28}$ R.V. Budny, M.G. Bell, H. Biglari, M. Bitter, C.E. Bush, C.Z. Cheng, E.D. Fredreickson, B. Grek, K.W. Hill, H. Hsuan, A.C. Janos, D.L. Jassby, D.W. Johnson, L.C. Johnson, B. LeBlanc, D.C. McCune, D.R. Mikkelsen, H.K. Park, A.T. Ramsey, S.A. Sabbagh, S.D. Scott, J.F. Schivell, J.D. Strachan, B.C. Stratton, E.J. Synakowski, G. Taylor, M.C. Zarnstorff, S.J .Zweben, Nucl. Fusion 32, 429 (1992). 
${ }^{29}$ K.M. McGuire, C.W. Barnes, S. Batha, M. Beer, M.G. Bell, R.E. Bell, A. Belov, H. Berk, S. Bernabei, M. Bitter, B. Breizman, N.L. Bretz, R. Budny, C.E. Bush, J. Callen, S. Cauffman, C.S. Chang, Z. Chang, C.Z. Cheng, G.A. Cottrell, D.S. Darrow, R.O. Dendy, W. Dorland, H. Duong, P.C. Efthimion, D. Ernst, H. Evenson, N.J. Fisch, R. Fisher, R.J. Fonck, C. Forest, E.D. Fredreickson, G.Y. Fu, H.P. Furth, N.N. Gorelenkov, V.Ya. Goloborod'ko, B. Grek, L.R. Grisham, G.W. Hammett, G.R. Hanson, R.J. Hawryluk, W. Heidbrink, H.W. Herrmann, M. Herrmann, K.W. Hill, J. Hogan, B. Hooper, J.C. Hosea, W.A. Houlberg, M. Hughes, R.A. Hulse, D.L. Jassby, F.C. Jobes, D.W. Johnson, R. Kaita, S. Kaye, J. Kesner, J.S. Kim, M. Kissick, A.V. Krasilnikov, H. Kugel, A. Kumar, N.T. Lam, P. Lamarche, B. LeBlanc, F.M. Levinton, C. Ludescher, L. Muchuzak, R.P. Majeski, J. Manikam, D.K. Mansfield, M. Mauel, E. Mazzucato, J. McChesney, D.C. McCune, G. McKee, D.M. Meade, S.S. Medley, R. Mika, D.R. Mikkelsen, S.V. Mirnov, D. Mueller, Y. Nagayama, G.A. Navratil, R. Nazikian, M. Okabayashi, D.K. Owens, H.K. Park, W. Park, P. Parks, S.F. Paul, M.P. Petrov, C.K. Phillips, M. Phillips, P. Phillips, A.T. Ramsey, M.H. Redi, G. Rewoldt, S. Reznik, A.L. Roquemore, J. Rogers, E. Ruskov, S.A. Sabbagh, M. Sasao, G. Schilling, J. Schivell, G.L. Schmidt, S.D. Scott, I. Semenov, T. Senko, A. Sesnic, C.H. Skinner, T. Stevenson, E.J. Strait, B.C. Stratton, J.D. Strachan, W. Stodiek, E. Synakowski, H. Takajashi, W. Tang, G. Taylor, J. Terry, M.E. Thompson, S. Von Goeler, A. Von Halle, R.T. Walters, S. Wang, R. White, R.M. Wieland, M. Williams, J.R. Wilson, K.L. Wong, G.A. Wurden, M. Yamada, V. Yavorski, K.M. Young, L. Zakharov, M.C. Zarnstorff, S.J. Zweben, in Plasma Physics and Controlled Nuclear Fusion Research (Proc. 16th Int. Conf., Montréal, 1996) (International Atomic Energy Agency, Vienna, in press), Paper F1-CN-64/01-2. 